\title{
Reactivity of Al-rich Alloys with Water Promoted by Liquid Al Grain Boundary Phases
}

Tiantian He, Wei Wang*, Wei Chen, Demin Chen*, Ke Yang

Institute of Metal Research, Chinese Academy of Sciences, Shenyang 110016, China

[Received 10 June 2015; Received in revised from 18 August 2015; Accepted 19 August 2015]

* Corresponding author. Ph.D.; Tel.: +86 24 23971541; Fax: +86 2423891320.

E-mail address: wei.wang@imr.ac.cn (W. Wang).

* Corresponding author. Ph.D.; Tel.: +86 24 23971641; Fax: +86 2423891320.

E-mail address: demin.chen.1@imr.ac.cn (D.M. Chen).

Al-Ga-Sn, Al-Ga-In and Al-Ga-In-Sn alloys were prepared using arc melting technique. Their microstructures were investigated by X-ray diffraction and scanning electron microscope with energy dispersed X-ray. Based on microstructure analysis, the phase constituents of alloys at $\mathrm{Al}$ grain boundaries were identified. The melting points of Al grain boundary phases were measured using differential scanning calorimeter. The reactivities of Al-water at different water temperatures indicate that liquid $\mathrm{Al}$ grain boundary phases promote Al-water reactions of alloys. The melting points of $\mathrm{Al}$ grain boundary phases affect the reaction temperatures of $\mathrm{Al}$-water, leading to different reaction temperatures of alloys. The measured $\mathrm{H}_{2}$ generation rate and yields of alloys are related to the compositions of alloys. The theory of micro-galvanic cell is used to explain the observed different $\mathrm{H}_{2}$ generation rates of alloys.

Key words: Al alloy; Microstructure; Composition; Reaction; Hydrogen generation rate

\section{Introduction}

$\mathrm{Al}$ as a high-capacity energy storage material has received much attention for $\mathrm{H}_{2}$ producing applications ${ }^{[1-8]}$. Pure $\mathrm{Al}$, however, is not capable of producing $\mathrm{H}_{2}$ from water because a thin oxide film on $\mathrm{Al}$ surfaces prohibits $\mathrm{Al}$ to react with water ${ }^{[9-14]}$. Alloying $\mathrm{Al}$ with low melting point metals ( $\mathrm{Ga}, \mathrm{In}, \mathrm{Sn}$ ) was suggested a feasible way of producing $\mathrm{H}_{2}$ from water $^{[15-18]}$, for those metals may disrupt Al oxide film formed on Al. Bulk alloys containing low melting point metals can split water at a mild temperature ${ }^{[19-21]}$, exhibiting a huge potential of $\mathrm{H}_{2}$ producing applications if those low melting point metals are fully recycled.

The mechanism of $\mathrm{Al}$ splitting water was ascribed to the low melting point phases formed 
in alloys, through which $\mathrm{Al}$ atoms of $\mathrm{Al}$ grains are able to diffuse and reach reaction sites to split water. Previous results ${ }^{[22,23]}$ found that the reaction temperature of $\mathrm{Al}$ with water is closely related to the melting point of $\mathrm{Al}$ grain boundary (GB) phases in alloys. For example, in the Al-Ga-In-Sn quaternary system, the alloys displayed reactivity at a temperature above the freezing point of water, lower than the Ga-In-Sn eutectic melting point of $10.7{ }^{\circ} \mathrm{C}^{[24]}$. Al-Ga binary alloys are observed to produce $\mathrm{H}_{2}$ at a reaction temperature of about $26{ }^{\circ} \mathrm{C}^{[19]}$, very close to the melting point of Al-Ga eutectic ${ }^{[25]}$. These results suggested that the higher the melting point of the reaction-enabling phases, the higher the reaction temperature of Al-water. In other words, the reaction temperature of Al-water can be adjusted by modifying the melting point of the low melting point phases in alloys. It is no doubt that this is important for the application of alloys if their reaction temperatures are controllable. According to phase diagrams ${ }^{[26,27]}$, the melting points of Ga-In and Ga-Sn binary eutectics are $15.3{ }^{\circ} \mathrm{C}$ and $20.5{ }^{\circ} \mathrm{C}$, respectively. These binary eutectics can act as reaction-enabling phases to initiate the reactivity of Al alloys with water. So far, research work on the reactivity of Al-Ga-In and Al-Ga-Sn alloys with water is scarce. Whether these alloys will react with water at a low or a high reaction temperature is unknown.

In this paper, Al-Ga-Sn, Al-Ga-In and Al-Ga-In-Sn alloys were prepared, and their reactivity with water was performed at different temperatures. The reaction temperatures of alloys were investigated and compared with the melting points of Ga-In and Ga-Sn binary eutectics together with the previously reported results. Mechanism of reactivity of alloys with water was discussed.

\section{Experimental details}

Al-Ga-Sn, Al-Ga-In, and Al-Ga-In-Sn alloy ingots with different compositions were prepared by using arc melting technique. The mass ratio of $\mathrm{Ga} / \mathrm{Sn}$ and $\mathrm{Ga} / \mathrm{In}$ is $1.73: 1$ for Al-Ga-Sn and Al-Ga-In alloys, and the mass ratio of $\mathrm{Ga} / \mathrm{In} / \mathrm{Sn}$ is 3.8:1.5:0.7 for Al-Ga-In-Sn alloy. Those ingots were melted under high purity argon atmosphere in a water-cooled copper crucible for several times to ensure a homogenous composition.

The phase compositions of alloys were identified by X-ray diffraction (XRD) using a Rigaku D/max 2400 diffractometer with monochromated $\mathrm{Cu} K_{\alpha}$ radiation $\left(\lambda_{k \alpha 1}=0.154056 \mathrm{~nm}\right)$. The fracture morphologies of alloys were characterized by using an FEI Inspect F50 scanning electron microscope (SEM) with a Quanta 600 EDX (Energy Dispersed X-ray) system. In order to minimize the oxidation of the fresh fracture surface, all samples were placed into the sample 
chamber as soon as they were broken. The equilibrium solubility of $\mathrm{Ga}$ in $\mathrm{Al}$ at room temperature is about $15 \mathrm{wt} \%$, but In and Sn are nearly immiscible in Al. Hence, part of Ga and most In and Sn will precipitate at Al grain boundaries after the solidification of alloys, leading to brittleness of the prepared alloys. Since the alloys are fractured in an intergranular manner, Al grains and grain boundary phases are observed directly using SEM.

A differential scanning calorimeter (DSC) Q1000 made by TA Instruments (New Castle, DE) was used to measure the melting points of Al grain boundary phases. The instrument was calibrated by testing the melting point of a reference material (In). Samples of about $40 \mathrm{mg}$ were run using Al pans under flowing purified argon. One heating and cooling cycle was conducted on samples in a temperature range from -30 to $300{ }^{\circ} \mathrm{C}$ with a constant heating and cooling rate of $10{ }^{\circ} \mathrm{C} / \mathrm{min}$.

The equipment used in $\mathrm{H}_{2}$ generation experiments is shown in previous work ${ }^{[22,23]}$. A 250-ml Pyrex glass reactor containing $200 \mathrm{ml}$ of distilled water was placed in a water bath to maintain a constant temperature. After the reactor reached the targeted temperature, the sample placed on a tray above the water level was dropped into the water. The weight of ejected water due to $\mathrm{H}_{2}$ release was recorded automatically using a one ten-thousandth scale, and then these data and reaction time were stored in a computer. The water mass was converted to $\mathrm{H}_{2}$ generated volume under the standard conditions ( $273 \mathrm{~K}, 1 \mathrm{~atm})$ using the ideal gas equation. The reactions of Al-water were conducted at different water temperatures. For each ex periment, the mass added into the reactor was about $0.3 \mathrm{~g}$, and the testing was repeated at least three times. The averaged $\mathrm{H}_{2}$ generation rates were also calculated for each comparison of reaction rate of different samples. In this calculation, the data of $\mathrm{H}_{2}$ yield below $50 \%$ of $\mathrm{H}_{2}$ production curve was selected to extract the $\mathrm{H}_{2}$ generation rate of a sample. Its value was obtained by calculation the slope of the selected curve using linear curve fitting. The results given here represent the averages for three repeated measurements.

\section{Results and Discussion}

\subsection{XRD analysis}

Fig. 1 shows the XRD patterns of Al-Ga-Sn and Al-Ga-In alloys. All samples contain crystalline Al. Besides Al, In and Sn phases are found in Al-Ga-In and Al-Ga-Sn alloys, respectively. Similar to previous observation ${ }^{[22,23]}$, intermetallic compound $\operatorname{In}_{3} \operatorname{Sn}(\beta)$ phases are found in Al-Ga-In-Sn alloy (not given). 


\subsection{SEM and EDX observations}

Fig. 2 shows SEM images of fracture surface of Al-Ga-Sn and Al-Ga-In alloys. Al grains are columnar showing obvious directional growth of Al grains during solidification of alloys. Their grain sizes (column width) range from 30 to $60 \mu \mathrm{m}$. EDX analysis (Tables 1 and 2) shows that $\mathrm{Al}$ grains mainly contain $\mathrm{Al}$ and little $\mathrm{Ga}$. Al grain surfaces are covered with lots of dispersed white or grey phases, whose shape and size depend strongly on the composition of alloys.

As shown in Fig. 2(a) and (b), when contents of low melting point (1.m.p) metals in Al-Ga-Sn alloys are below $10 \mathrm{wt} \%$, the GB phases are granular and rode-like, and their sizes increase with rising the contents of 1.m.p metals in alloys. The EDX analysis shows that the phases contain lots of $\mathrm{Sn}$, little $\mathrm{Ga}$ and $\mathrm{Al}$. The atomic ratio of $\mathrm{Al}: \mathrm{Sn}$ in most phases is close to the Al:Sn atomic ratio of 2.1:97.9 of Al-Sn binary eutectics under equilibrium solidification ${ }^{[28]}$. Therefore, those GB phases are identified as Al-Sn binary eutectics. When contents of 1.m.p metals in alloys are higher (> $10 \mathrm{wt} \%$ ), the sizes of GB phases become bigger and the compositions are inhomogeneous. Besides little amount of isolated Al-Sn binary eutectics particles, many GB phases are presented with bigger plates, which are mixtures containing Al-Sn binary eutectics and Ga-rich phases. As indicated in Fig. 2(d), in contrast to the bright white Al-Sn eutectics, the Ga-rich phases are dark grey, and Al and Ga rich, but lack of Sn. The Ga:Sn atomic ratios of those Ga-rich phases are scattered as detected by EDX. The measured $\mathrm{Ga}: \mathrm{Sn}$ atomic ratios range from about $4: 1$ to $11: 1$, indicating that some phases are Al-Ga-Sn eutectics as their atomic ratios approach 88.9:7.9 of Al-Ga-Sn ternary eutectics under equilibrium solidification ${ }^{[29,30]}$. But the Ga:Sn atomic ratios of others deviate markedly from 88.9:7.9, suggesting that those phases also contain extra $\mathrm{Sn}$ besides Al-Ga-Sn eutectics.

From Fig. 2(e)-(h), one can see that the Al-Ga-In alloys exhibit similar features of metallographic morphologies as those of Al-Ga-Sn alloys because of similar solidification process of two kinds of alloys. In Al-Ga-In alloys, Al-In binary and Al-Ga-In ternary eutectics are identified as pointed by arrows.

According to the liquidus projection of ternary phase diagram of Al-Ga-Sn alloys (Fig. 3), the mass percentages of structural components are calculated by mean of lever rule (Table 3). It can be seen that the amount of Al-Sn binary eutectics increases with increasing $\mathrm{Ga}$ and $\mathrm{Sn}$ content as their content in alloys is below $10 \mathrm{wt} \%$. However, their amount reduces due to the presence of Al-Ga-Sn ternary eutectics when Ga and Sn content is above $10 \mathrm{wt} \%$. With further increasing the content of $\mathrm{Ga}$ and $\mathrm{Sn}$, the amount of $\mathrm{Al}-\mathrm{Ga}-\mathrm{Sn}$ eutectic increases. The results 
indicate that both the type and mass percentage of phase components at $\mathrm{Al}$ grain boundaries are closely related to the content of 1.m.p metals added in alloys, for these metals will form different phases at $\mathrm{Al}$ grain boundaries during solidification. Due to lack of liquidus projection of ternary phase diagram of Al-Ga-In alloys, the mass percentages of structural components of the alloys are not extracted.

\subsection{DSC findings}

Fig. 4 shows the DSC curves of Al-Ga-Sn and Al-Ga-In alloys tested at the heating cycle. As the content of 1.m.p metals of Ga and $\mathrm{Sn}$ in Al-Ga-Sn alloys is below $10 \mathrm{wt} \%$, only one endothermal peak is seen in DSC traces with a peak temperature of about $218{ }^{\circ} \mathrm{C}$, which is close to the melting point of Al-Sn binary eutectic of $228{ }^{\circ} \mathrm{C}^{[28]}$. When the content of $\mathrm{Ga}$ and $\mathrm{Sn}$ is above $10 \mathrm{wt} \%$, besides the peak at $218{ }^{\circ} \mathrm{C}$, a sharp endothermal peak of about $18.9{ }^{\circ} \mathrm{C}$ is detected, which is very close to the melting point of Al-Ga-Sn ternary eutectic of $19{ }^{\circ} \mathrm{C}^{[29]}$. This peak displays higher intensity with the increase of the content of $\mathrm{Ga}$ and $\mathrm{Sn}$ in alloys, implying that the higher the content of $\mathrm{Ga}$ and $\mathrm{Sn}$, the more the Al-Ga-Sn ternary eutectics in Al-Ga-Sn alloys. Additionally, a wide endothermal peak is observed with a peak temperature of about 120 ${ }^{\circ} \mathrm{C}$ in DSC curve of $15 \mathrm{wt} \% \mathrm{Al}-\mathrm{Ga}-\mathrm{Sn}$. This peak may be caused by more extra Ga dissolving in $\mathrm{Al}-\mathrm{Sn}$ eutectics and giving rise to an extended melting range of the Ga and Al-Sn eutectic mixtures upon liquefaction.

Similar to Al-Ga-Sn alloys, a small endothermal peak at about $152{ }^{\circ} \mathrm{C}$ is shown in Al-Ga-In alloys, as a result of melting of Al-In binary eutectic, whose melting point is $156{ }^{\circ} \mathrm{C}$ ${ }^{[31]}$. The $15 \mathrm{wt} \% \mathrm{Al}-\mathrm{Ga}-\mathrm{In}$ alloy also displays a sharp peak at $15{ }^{\circ} \mathrm{C}$ and a diffusive peak at 82 ${ }^{\circ} \mathrm{C}$, which corresponds to the melting of Al-Ga-In ternary eutectics, and Ga and Al-Sn eutectic mixtures, respectively. From Fig. 4, the melting points of eutectics of Al-Ga-Sn and Al-Ga-In alloys are extracted to be $18.9{ }^{\circ} \mathrm{C}$ and $15{ }^{\circ} \mathrm{C}$, respectively, higher than the measured melting point of Al-Ga-In-Sn eutectic $\left(10.7{ }^{\circ} \mathrm{C}^{[24]}\right)$.

\subsection{Performance of $\mathrm{H}_{2}$ generation}

The reactivity of the Al-Ga-Sn and Al-Ga-In alloys with water was tested at different water temperatures using the $\mathrm{H}_{2}$ measurement apparatus, and their reaction temperatures are roughly estimated. Fig. 5 shows $\mathrm{H}_{2}$ production curves of Al-Ga-Sn alloys at different water temperatures. When the Ga and Sn content in alloys is below $10 \mathrm{wt} \%$, the alloys did not show reactivity within the temperature range of from 10 to $70{ }^{\circ} \mathrm{C}$. The alloys with high content of $\mathrm{Ga}$ 
and $\mathrm{Sn}(>10 \mathrm{wt} \%)$, however, are observed to produce $\mathrm{H}_{2}$ at different reaction temperatures, even though their $\mathrm{H}_{2}$ yields are very low. For example, the $15 \mathrm{wt} \%$ alloy reacts with water at about $20{ }^{\circ} \mathrm{C}$, but $12 \mathrm{wt} \%$ and $10 \mathrm{wt} \%$ alloys at about $30{ }^{\circ} \mathrm{C}$. The $\mathrm{H}_{2}$ yield of $15 \mathrm{wt} \%$ alloy is $12 \%$, and the $\mathrm{H}_{2}$ yields of $10 \mathrm{wt} \%$ and $12 \mathrm{wt} \%$ alloys are below $10 \%$. The remains of reaction were observed using SEM to look for the reasons that $\mathrm{Al}$ is not depleted. From the SEM, it is noted that $\mathrm{Al}$ surfaces of remains contain lots of oxygen, and their color turns from silver white into dark grey.

From Fig. 5, one can see that the $\mathrm{H}_{2}$ yields show an increasing trend with increasing water temperature. At a water temperature of $70{ }^{\circ} \mathrm{C}$, the $\mathrm{H}_{2}$ yields of $10 \mathrm{wt} \%, 12 \mathrm{wt} \%$ and $15 \mathrm{wt} \%$ alloy are $25 \%, 70 \%$ and $90 \%$, respectively, indicating the big difference of $\mathrm{H}_{2}$ yields of those alloys. From Fig. 5, the $\mathrm{H}_{2}$ generation rates of alloys are calculated, and their relations with $\mathrm{Ga}$ and Sn content at different water temperatures are plotted in Fig. 6. At the same water temperature, the $\mathrm{H}_{2}$ generation rates of alloys increase with increasing $\mathrm{Ga}$ and $\mathrm{Sn}$ content when $\mathrm{Ga}$ and Sn content is higher than $10 \mathrm{wt} \%$.

Fig. 7 shows $\mathrm{H}_{2}$ production curves of Al-Ga-In alloys at different water temperatures. Different from the reactivity of Al-Ga-Sn alloys, the Al-Ga-In alloys displayed reactivity at about $10{ }^{\circ} \mathrm{C}$. The $\mathrm{H}_{2}$ yields are above $90 \%$ for $3 \mathrm{wt} \%$ alloy at $50{ }^{\circ} \mathrm{C}$ and $15 \mathrm{wt} \%$ alloy at $20{ }^{\circ} \mathrm{C}$, indicating the nearly complete consumption of $\mathrm{Al}$ in those alloys. Fig. 8 shows the calculated $\mathrm{H}_{2}$ generation rates of Al-Ga-In alloys at different water temperatures. The calculated results of $15 \mathrm{wt} \% \mathrm{Al}-\mathrm{Ga}-\mathrm{Sn}$ alloy and $15 \mathrm{wt} \% \mathrm{Al-Ga-In-Sn}$ alloy are also plotted in this figure. As shown in Fig. 8, the $\mathrm{H}_{2}$ generation rates of $15 \mathrm{wt} \%$ Al-Ga-In alloys are higher than those of $3 \mathrm{wt} \%$ alloys. With increasing water temperatures, the $\mathrm{H}_{2}$ generation rates of $3 \mathrm{wt} \%$ Al-Ga-In alloy increase slightly, but the $\mathrm{H}_{2}$ generation rates of $15 \mathrm{wt} \%$ Al-Ga-In alloy increase significantly. When water temperatures are below $30{ }^{\circ} \mathrm{C}$, the $\mathrm{H}_{2}$ generation rates of $15 \mathrm{wt} \%$ Al-Ga-In and Al-Ga-Sn alloys are lower than those of 15 wt\% Al-Ga-In-Sn alloy. However, when water temperatures are above $30{ }^{\circ} \mathrm{C}$, the $15 \mathrm{wt} \% \mathrm{Al}-\mathrm{Ga}-\mathrm{In}$ alloy exhibits the lowest $\mathrm{H}_{2}$ generation rate, but the $15 \mathrm{wt} \% \mathrm{Al-Ga-Sn}$ alloy exhibits the highest one. For example, at a water temperature of $70{ }^{\circ} \mathrm{C}$, the $\mathrm{H}_{2}$ generation rate of $15 \mathrm{wt} \%$ Al-Ga-In, Al-Ga-In-Sn and Al-Ga-Sn alloys are 583, 1256, $1595 \mathrm{ml} / \mathrm{min} \mathrm{g} \mathrm{Al}$, respectively.

\subsection{Discussion}

Present and previous experiments confirmed that the observed Al splitting water reaction is promoted by liquid GB phases, such as: Al-Ga-In-Sn, Al-Ga-Sn, Al-Ga-In and Al-Ga 
eutectics, since those GB phases on Al not only protect $\mathrm{Al}$ from oxidation but also provide a pathway for $\mathrm{Al}$ diffusion to the reaction site as well. Considering the reaction of an $\mathrm{Al}$ grain with part of surface covered with GB phases in water, Al embedded in GB phases react with water firstly because the GB phases contain a certain amount of Al. The reaction depletes the equilibrium concentrations of $\mathrm{Al}$ in GB phases. Clearly, if the GB phases are solid, $\mathrm{Al}$ atoms of $\mathrm{Al}$ grain is not likely to enter into the GB phases to compensate the $\mathrm{Al}$ consumed by reaction with water in $\mathrm{GB}$ phases. Once $\mathrm{Al}$ in the $\mathrm{GB}$ phases contacting water is all consumed, Al-water reaction suspends. For this reason, it is often observed that a slight of bubbles emit from the sample surface for about tens of seconds, and then disappear, indicating that Al-water reaction is not really initiated. However, when the GB phases are liquid (the water temperature is higher than the melting point of GB phases), Al embedded in GB phases diffuses freely in the liquid. As a result, $\mathrm{Al}$ atoms of $\mathrm{Al}$ grain covered by $\mathrm{GB}$ phases will enter into the liquid to restore the Al concentration of liquid. This was confirmed by the SEM observation that a large number of Al nanoparticles (about 50-100 nm in diameter) were embedded in the Ga-In-Sn eutectic phase ${ }^{[20]}$. During the reaction, the resulting hydroxide precipitates will be swept away by $\mathrm{H}_{2}$ bubbles and escape from the surfaces of GB phases. Meanwhile, the surfaces of GB phases move inwards due to mass lose of $\mathrm{Al}$ on the covering area of $\mathrm{GB}$ phases. As $\mathrm{Al}$ continues to diffuse into $\mathrm{GB}$ phases, $\mathrm{Al}$ reacts with water continuously until all of $\mathrm{Al}$ in alloy is consumed.

Clearly, the mechanism of Al-water reaction works based on the presence of liquid phases at $\mathrm{Al}$ grain GBs. When $\mathrm{Ga}$ and $\mathrm{Sn}$ content in $\mathrm{Al}-\mathrm{Ga}-\mathrm{Sn}$ alloys is below $10 \mathrm{wt} \%$, the alloys just contain Al-Sn binary eutectic (which melting point is $218{ }^{\circ} \mathrm{C}$ ), whereas Al-Ga-Sn ternary eutectics are absent. As a result, the Al-Ga-Sn alloys are unable to split water. However, when $\mathrm{Ga}$ and $\mathrm{Sn}$ content in Al-Ga-Sn alloys reaches $10 \mathrm{wt} \%$, due to the presence of Al-Ga-Sn ternary eutectics with a melting point of $18.9{ }^{\circ} \mathrm{C}$ in alloys, $\mathrm{Al}$ is capable of reacting with water.

The mechanism of Al-water reaction predicts that there exists a critical reaction temperature related to the melting point of GB phases for each alloy. When water temperature is below the reaction temperature of an alloy, $\mathrm{Al}$ is inert in water. Once water temperature approaches or is up to the reaction temperature of an alloy, Al begins to react with water. Therefore, it is reasonable that the alloys exhibit different reaction temperatures, because of different melting points of those GB phases in alloys. As observed from experiments, Al-Ga-In-Sn and Al-Ga-In alloys are capable of splitting water at about $1{ }^{\circ} \mathrm{C}^{[22,23]}$ and $10{ }^{\circ} \mathrm{C}$, respectively. Their reaction temperatures are smaller than their melting points of GB phases. However, the reaction temperatures of $15 \mathrm{wt} \% \mathrm{Al}-\mathrm{Ga}-\mathrm{Sn}$ and $50 \mathrm{wt} \% \mathrm{Al}-50 \mathrm{wt} \% \mathrm{Ga}$ alloys are about $20{ }^{\circ} \mathrm{C}$ and $26{ }^{\circ} \mathrm{C}^{[19]}$, respectively, close to their melting points of GB phases. The results 
indicate that the alloys react with water at higher temperatures as their melting points of GB phases are higher, for the melting point of GB phases follows sequence of $T_{\mathrm{AG}}>T_{\mathrm{GS}}>T_{\mathrm{GI}}>$ $T_{\mathrm{GIS}}(\mathrm{A}, \mathrm{G}, \mathrm{I}, \mathrm{S}$ refer to $\mathrm{Al}, \mathrm{Ga}, \mathrm{In}, \mathrm{Sn}$, respectively), consistent with the temperature sequence of Al-water reaction of alloys. It is noted that the reaction temperatures of some alloys, such as: Al-Ga-In and Al-Ga-In-Sn alloys display a few degree Celsius lower compared with their melting points of GB phases. The results seem to conflict with the reaction mechanism mentioned above, as the GB phases are solid in alloys at those lower water temperatures. In fact, $\mathrm{Al}$ solvated in GB phases can react with water. Since the reaction releases a large amount of heat, the temperature is increased at the local reacting region. If the releasing heat induces GB phases transform from solid to liquid, Al will react with water continuously.

Compared with $15 \mathrm{wt} \%$ Al-Ga-Sn alloy, the $10 \mathrm{wt} \%$ and $12 \mathrm{wt} \%$ Al-Ga-Sn alloys exhibit a higher reaction temperature of about $30{ }^{\circ} \mathrm{C}$, although they contain Al-Ga-Sn eutectic with the same a melting point of $20{ }^{\circ} \mathrm{C}$ as $15 \mathrm{wt} \% \mathrm{Al}-\mathrm{Ga}-\mathrm{Sn}$ alloy (Fig. 4). The result is inconsistent with the theory that $\mathrm{Al}$ reacts with water at a temperature approaching the melting point of GB phase. Since the later two alloys consist of less Al-Ga-Sn eutectic than the former one (Fig. 4), the less GB phase is ascribed to the observed higher reaction temperature of $10 \mathrm{wt} \%$ and 12 wt\% Al-Ga-Sn alloys. In fact, when Al reacts with water, Al grain surface is passivated continuously during the reaction. If gas flow of $\mathrm{H}_{2}$ bubbles is intense enough as a result of vigorous reaction of Al-water, the passivated hydroxide film on Al will be swept away so that the fresh $\mathrm{Al}$ surface is exposed, sustaining the reaction until most $\mathrm{Al}$ is depleted. Conversely, an Al hydroxide layer will be formed on the fresh Al surface. The reaction will retard or stop if the adhesive hydroxide layer on $\mathrm{Al}$ attains a critical value. As the $10 \mathrm{wt} \%$ and $12 \mathrm{wt} \% \mathrm{Al}-\mathrm{Ga}-\mathrm{Sn}$ alloys contain less GB phase, it is likely that the generated $\mathrm{H}_{2}$ bubbles of reaction are unable to disrupt the hydroxide film formed on Al. Thus, it is reasonable that they are not capable of splitting water at $20{ }^{\circ} \mathrm{C}$. When the water temperature rises up to $30{ }^{\circ} \mathrm{C}$, the amount of $\mathrm{Al}-\mathrm{Ga}-\mathrm{Sn}$ eutectic will increase due to the reaction of original Al-Ga-Sn eutectic in alloys with neighboring Al-Sn eutectic. In addition, Al also reacts with water quickly at a higher temperature. These factors result in Al to split water continuously.

Although the above theory can explain well the reaction temperatures of alloys, but it is difficult to explain the observed reaction rates and yields of alloys. Results show that when the water temperature is above $30{ }^{\circ} \mathrm{C}$, the $\mathrm{H}_{2}$ generation rate of $15 \mathrm{wt} \% \mathrm{Al}-\mathrm{Ga}-\mathrm{In}-\mathrm{Sn}$ alloy is not highest anymore. Instead, the $15 \mathrm{wt} \% \mathrm{Al}-\mathrm{Ga}-\mathrm{Sn}$ alloy exhibits the highest $\mathrm{H}_{2}$ generation rate, while the $15 \mathrm{wt} \%$ Al-Ga-In alloy exhibits the lowest one. The result suggests that Al-water reaction speed of alloys is not determined by the melting point, but by the compositions of 
eutectic GB phases. The theory of micro-galvanic cell ${ }^{[32-36]}$, which is often used to explain $\mathrm{Al}$ corrosion in many $\mathrm{Al}$ alloys, can be used to interpret the observed phenomenon of reactions. In an $\mathrm{Al}$ alloy and water system, $\mathrm{Al}$ and another metal will form a micro-galvanic cell when contacting water due to their difference of electrode potential. As a result, Al takes as the anode and obtains an electron to produce unstable $\mathrm{Al}(\mathrm{OH})_{3}$ species, but the other metal takes as the cathode where water loses an electron to generate $\mathrm{H}_{2}$. The corrosion rate of $\mathrm{Al}$ depends strongly on the electrode potential of $\mathrm{Al}$ and its contacting metals. Al corrodes fast if electrode potential of Al-Metal is higher. Considering the scenario that $\mathrm{Al}$ embedded in liquid GB phases reacts with water. Since Al moves freely in GB phases, Al will separately form micro-galvanic cells with neighboring metals, such as $\mathrm{Sn}-\mathrm{Al}$ in Al-Ga-Sn eutectic, In-Al in Al-Ga-In eutectic besides $\mathrm{Ga}-\mathrm{Al}$. According to calculations ${ }^{[36]}$, the electrode potentials of $\mathrm{Sn}-\mathrm{Al}, \mathrm{In}-\mathrm{Al}$ and $\mathrm{Ga}-\mathrm{Al}$ are estimated to be $-1.53,-1.33$ and $-1.15 \mathrm{~V}$, respectively. The trend of the dissolution of $\mathrm{Al}$ in water will follow the order of $\mathrm{Sn}-\mathrm{Al}>\mathrm{In}-\mathrm{Al}>\mathrm{Ga}-\mathrm{Al}$. Therefore, the Al-Ga-In alloy exhibits the lowest $\mathrm{H}_{2}$ generation rate and Al-Ga-Sn alloy exhibits the highest one. Although the Al-Ga-Sn alloys exhibit the highest $\mathrm{H}_{2}$ generation rates, but their yields are lowest among the three kinds of alloys. So far, the reason why Al-Ga-Sn alloys display the lowest yields is still unknown.

\section{Conclusion}

Present experiments indicate that Al-water reaction of alloys is promoted by the formation of liquid eutectic phases at $\mathrm{Al}$ grain boundary, by which $\mathrm{Al}$ atoms of $\mathrm{Al}$ grains diffuse to the reaction sites to react with water continuously. The melting point of GB phases affect the reaction temperatures of alloys. Al reacts with water at higher temperatures as the melting points of GB phases in alloys are higher. Compared with 15 wt\% Al-Ga-In-Sn and Al-Ga-In alloys, the $15 \mathrm{wt} \%$ Al-Ga-Sn alloy exhibits the highest $\mathrm{H}_{2}$ generation rate and the lowest yield, suggesting that the reaction rates and yields of alloys are not determined by the melting points of GB phases, but by compositions of them. The observed different $\mathrm{H}_{2}$ generation rates of alloys can be explained using the theory of micro-galvanic cell. Al-water reaction can be controlled by adjusting the compositions of low melting metals in alloys.

\section{Acknowledgements}

This work was financially supported by the National Science Foundation of China (Grant No. 51171201) and the National Basic Research Program of China (No. 2010CB631305). 


\section{References}

[1] H.Z. Wang, D.Y.C. Leung, M.K.H. Leung, M. Ni, Renew. Sust. Energ. Rev. 13 (2009) 845-853.

[2] S. Elitzur, V. Rosenband, A. Gany, Int. J. Hydrogen Energy 39 (2014) 6328-6334.

[3] Y.G. Liu, X.H. Wang, H.Z. Liu, Z.H. Dong, S.Q. Li, H.W. Ge, M. Yan, Energy 72 (2014) 421-426.

[4] M. Yamawaki, T. Nishihara, Y. Inagaki, K. Minato, H. Oigawa, K. Onuki, R. Hino, M. Ogawa, Int. J. Hydrogen Energy 32 (2007) 2719-2725.

[5] H.B. Zou, S.Z. Chen, Z.H. Zhao, W.M. Lin, J. Alloy. Compd. 578 (2013) 380-384.

[6] L. Soler, J. Macanas, M. Munoz, J. Casado, J. Power Sources 169 (2007) 144-149.

[7] B. Alinejad, K. Mahmoodi, Int. J. Hydrogen Energy 34 (2009) 7934-7938.

[8] X.Y. Chen, Z.W. Zhao, X.H. Liu, M.M. Hao, A.L. Chen, Z.Y. Tang, J. Power Sources 254 (2014) 345-352.

[9] L. Soler, A.M. Candela, J. Macanás, M. Muñoz, J. Casado, Int. J. Hydrogen Energy 35 (2010) 1038-1048.

[10] Z.Y. Deng, J.M.F. Ferreira, Y. Sakka, J. Am. Ceram. Soc. 91 (2008) 3825-3834.

[11] H.B. Dai, G.L. Ma, H.J. Xia, P. Wang, Energy Environ. Sci. 4 (2011) 2206-2212.

[12] F. Xu, L.X. Sun, X.F. Lan, H.L. Chu, Y.J. Sun, H.Y. Zhou, F. Li, L.N. Yang, X.L. Sic, J. Zhang, S. Walter, Z. Gabelica, Int. J. Hydrogen Energy 39 (2014) 5514-5521.

[13] S.S. Razavi-Tousi, J.A.Szpunar, Int. J. Hydrogen Energy 38 (2013) 795-806.

[14] Z.Y. Deng, Y.B. Tang, L.L. Zhu, Y. Sakka, J.H. Ye, Int. J. Hydrogen Energy 35 (2010 9561-9568.

[15] M.Q. Fan, F. Xu, L.X. Sun, Energy Fuel. 21 (2007) 2294-2298.

[16] H.H. Wang, Y. Chang, S.J. Dong, Z.F. Lei, Q.B. Zhu, P. Luo, Z.X. Xie, Int. J. Hydrogen Energy 38 (2013) 1236-1243.

[17] A.V. Parmuzina, O.V. Kravchenko, Int. J. Hydrogen Energy 33 (2008) 3073-3076.

[18] A.V. Ilyukhina, O.V. Kravchenko, B.M. Bulychev, E.I. Shkolnikov, Int. J. Hydrogen Energy 35 (2010) 1905-1910.

[19] J.T. Ziebarth, J.M. Woodall, R.A. Kramer, G. Choi, Int. J. Hydrogen Energy 36 (2011) 5271-5279.

[20] J.M. Woodall, J.T. Ziebarth, C.R. Allen, D.M. Sherman, J. Jeon, G. Choi, in: Proceedings of Materials Innovations in an Emerging Hydrogen Economy, Cocoa Beach, FL, Feb 24-27, 2008. 
[21] J.M. Woodall, J. Ziebarth, C.R. Allen, in: Proceedings of the ASME 2nd Energy Nanotechnology International Conference, Santa Clara, CA, Sept 5-7, 2007.

[22] W. Wang, D.M. Chen, K. Yang, Int. J. Hydrogen Energy 35 (2010) 12011-12019.

[23] W. Wang, X.M. Zhao, D.M. Chen, K. Yang, Int. J. Hydrogen Energy 37 (2012) 2187-2194.

[24] D.S. Evans, A. Prince, Met. Sci. 12 (1978) 411-414.

[25] J.L. Murray, J. Phase Equilib. 4 (1983) 183-190.

[26] T.J. Anderson, I. Ansara, J. Phase Equilib. 12 (1991) 64-72.

[27] T.J. Anderson, I. Ansara, J. Phase Equilib. 13 (1992) 181-189.

[28] A.J. McAlister, D.J. Kahan, J. Phase Equilib. 4 (1983) 410-414.

[29] V.G. Rivlin, P. Miodownik (Eds.), Ternary Alloys, Vol. 5, VCH Verlagsgesellschaft, Weinheim, Germany, 1992, pp. 614-623.

[30] M. Wolcyrz, R. Kubiak, S. Maciejewski, Phys. Status. Solidi. B 107 (1981) 245-253.

[31] J.L. Murray, J. Phase Equilib. 4 (1983) 271-278.

[32] I. Felhosi, H. Habazaki, K. Shimizu, P. Skeldon, G.E. Thompson, G.C. Wood, X. Zhou, Corros. Sci. 40 (1998) 2125-2139.

[33] Y.Y. Andreev, A.V. Goncharov, Electrochim. Acta 50 (2005) 2629-2637.

[34] J.T.B. Gundersen, A. Ayta, J.H. Nordlien, K. Nisancioglu, Corros. Sci. 46 (2004) 697-714.

[35] J.C. Liu, X.M. Zhang, M.G. Chen, L. Li, B. Zhu, J.G. Tang, S.D. Liu, Appl. Surf. Sci. 257 (2011) 4004-4009.

[36] D.D. Wagman, W.H. Evans, V.B. Parker, R.H. Schumm, I. Halow, S.M. Bailey, K.L. Churney, R.L. Nuttall, J. Phys. Chem. Ref. Data 11(Suppl. 2) (1982) 1. 


\section{$\underline{\text { Figure and table captions }}$}

Table 1 Compositions of Al-Ga-Sn alloys obtained using EDX

Table 2 Compositions of Al-Ga-In alloys obtained using EDX

Table 3 Structural components of Al-Ga-Sn alloys calculated by lever rule (wt \%)

Fig. 1. XRD patterns of Al-Ga-Sn and Al-Ga-In alloys: (a) 3 wt $\%$ Al-Ga-Sn, (b) 6 wt $\%$ Al-Ga-Sn, (c) 8 wt\% Al-Ga-Sn, (d) 10 wt $\%$ Al-Ga-Sn, (e) 12 wt $\%$ Al-Ga-Sn, (f) 15 wt $\%$ Al-Ga-Sn, (g) 15 wt\% Al-Ga-In, (h) 3 wt\% Al-Ga-In.

Fig. 2. Fracture surfaces of (a) and (b) 3 wt $\%$ Al-Ga-Sn alloys, (c) and (b) 15 wt $\%$ Al-Ga-Sn alloys, (e) and (f) 3 wt\% Al-Ga-In alloys, (g) and (h) 15 wt\% Al-Ga-In alloys.

Fig. 3. Phase diagram of Al-Ga-Sn alloy ${ }^{[29]}$.

Fig. 4. DSC curves of (a) Al-Ga-Sn and (b) Al-Ga-In alloys tested at the heating cycle.

Fig. 5. $\mathrm{H}_{2}$ production curves of $\mathrm{Al}-\mathrm{Ga}-\mathrm{Sn}$ alloys measured at water temperatures of (a) $10{ }^{\circ} \mathrm{C}$, (b) $20{ }^{\circ} \mathrm{C}$, (c) $30{ }^{\circ} \mathrm{C}$, (d) $50{ }^{\circ} \mathrm{C}$, (e) $60{ }^{\circ} \mathrm{C}$, (f) $70{ }^{\circ} \mathrm{C}$.

Fig. 6. $\mathrm{H}_{2}$ generation rates of $\mathrm{Al}-\mathrm{Ga}-\mathrm{Sn}$ alloys as a function of $\mathrm{Ga}-\mathrm{Sn}$ content.

Fig. 7. $\mathrm{H}_{2}$ production curves of (a) $3 \mathrm{wt} \%$, (b) $15 \mathrm{wt} \%$ Al-Ga-In alloys measured at different water temperatures.

Fig. 8. $\mathrm{H}_{2}$ generation rates of Al-Ga-In, Al-Ga-Sn and Al-Ga-In-Sn alloys as a function of water temperatures. 
Table List

Table 1

\begin{tabular}{|c|c|c|c|c|c|}
\hline \multirow{2}{*}{ Sample } & \multirow{2}{*}{ Spectrum } & \multirow{2}{*}{ Phase } & \multicolumn{3}{|c|}{ Element (at.\%) } \\
\hline & & & $\mathrm{Al}$ & $\mathrm{Ga}$ & $\mathrm{Sn}$ \\
\hline \multirow[t]{2}{*}{$3 \mathrm{wt} \%$} & 1 & $\mathrm{G}$ & 98.12 & 1.88 & 0.00 \\
\hline & 2 & GB & 53.15 & 3.11 & 43.74 \\
\hline \multirow[t]{2}{*}{$6 \mathrm{wt} \%$} & 3 & $\mathrm{G}$ & 97.71 & 2.29 & 0.00 \\
\hline & 4 & GB & 21.21 & 5.67 & 73.12 \\
\hline \multirow[t]{2}{*}{$8 \mathrm{wt} \%$} & 5 & $\mathrm{G}$ & 97.36 & 2.64 & 0.00 \\
\hline & 6 & GB & 33.32 & 5.33 & 61.35 \\
\hline \multirow[t]{3}{*}{$10 \mathrm{wt} \%$} & 7 & $\mathrm{G}$ & 96.78 & 3.22 & 0.00 \\
\hline & 8 & GB & 57.37 & 5.49 & 37.14 \\
\hline & 9 & GB & 66.74 & 31.69 & 1.57 \\
\hline \multirow[t]{3}{*}{$12 \mathrm{wt} \%$} & 10 & $\mathrm{G}$ & 96.29 & 3.71 & 0.00 \\
\hline & 11 & GB & 28.45 & 9.62 & 61.93 \\
\hline & 12 & GB & 30.49 & 61.84 & 7.67 \\
\hline \multirow[t]{3}{*}{$15 \mathrm{wt} \%$} & 13 & $\mathrm{G}$ & 95.79 & 4.21 & 0.00 \\
\hline & 14 & GB & 15.53 & 8.07 & 76.40 \\
\hline & 15 & GB & 57.95 & 35.60 & 6.45 \\
\hline
\end{tabular}

$\mathrm{G}$ : $\mathrm{Al}(\mathrm{Ga})$ grain, $\mathrm{GB}$ : grain boundary phase.

Table 2

\begin{tabular}{|c|c|c|c|c|c|}
\hline \multirow{2}{*}{ Alloy } & \multirow{2}{*}{ Spectrum } & \multirow{2}{*}{ Phase } & \multicolumn{3}{|c|}{ Element (at.\%) } \\
\hline & & & $\mathrm{Al}$ & $\mathrm{Ga}$ & In \\
\hline \multirow[t]{2}{*}{$3 \mathrm{wt} \%$} & 1 & $\mathrm{G}$ & 98.31 & 1.69 & 0.00 \\
\hline & 2 & GB & 66.16 & 1.45 & 32.39 \\
\hline \multirow[t]{4}{*}{$15 \mathrm{wt} \%$} & 3 & G & 95.03 & 4.97 & 0.00 \\
\hline & 4 & GB & 18.56 & 5.67 & 75.77 \\
\hline & 5 & GB & 50.40 & 7.06 & 42.54 \\
\hline & 6 & GB & 62.95 & 32.03 & 5.02 \\
\hline
\end{tabular}

$\mathrm{G}$ : $\mathrm{Al}(\mathrm{Ga})$ grain, GB: grain boundary phase. 
Table 3

\begin{tabular}{cccc}
\hline Sample & primary $\alpha-\mathrm{Al}$ & $(\mathrm{Al}-\mathrm{Sn})$ eutectic & (Al-Ga-Sn) eutectic \\
\hline $3 \mathrm{wt} \%$ & 95.61 & 4.39 & 0.00 \\
$6 \mathrm{wt} \%$ & 91.43 & 8.57 & 0.00 \\
$8 \mathrm{wt} \%$ & 88.63 & 11.37 & 0.00 \\
$10 \mathrm{wt} \%$ & 89.91 & 2.78 & 7.31 \\
$12 \mathrm{wt} \%$ & 87.85 & 3.30 & 8.85 \\
$15 \mathrm{wt} \%$ & 84.82 & 4.12 & 11.06 \\
\hline
\end{tabular}


Figure List

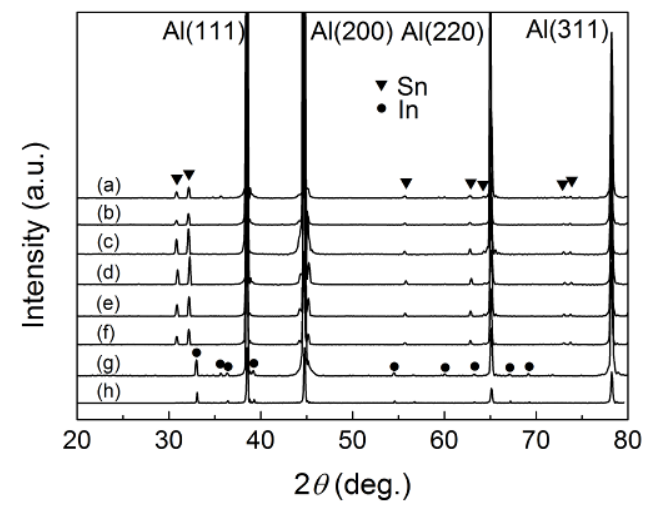

Fig. 1
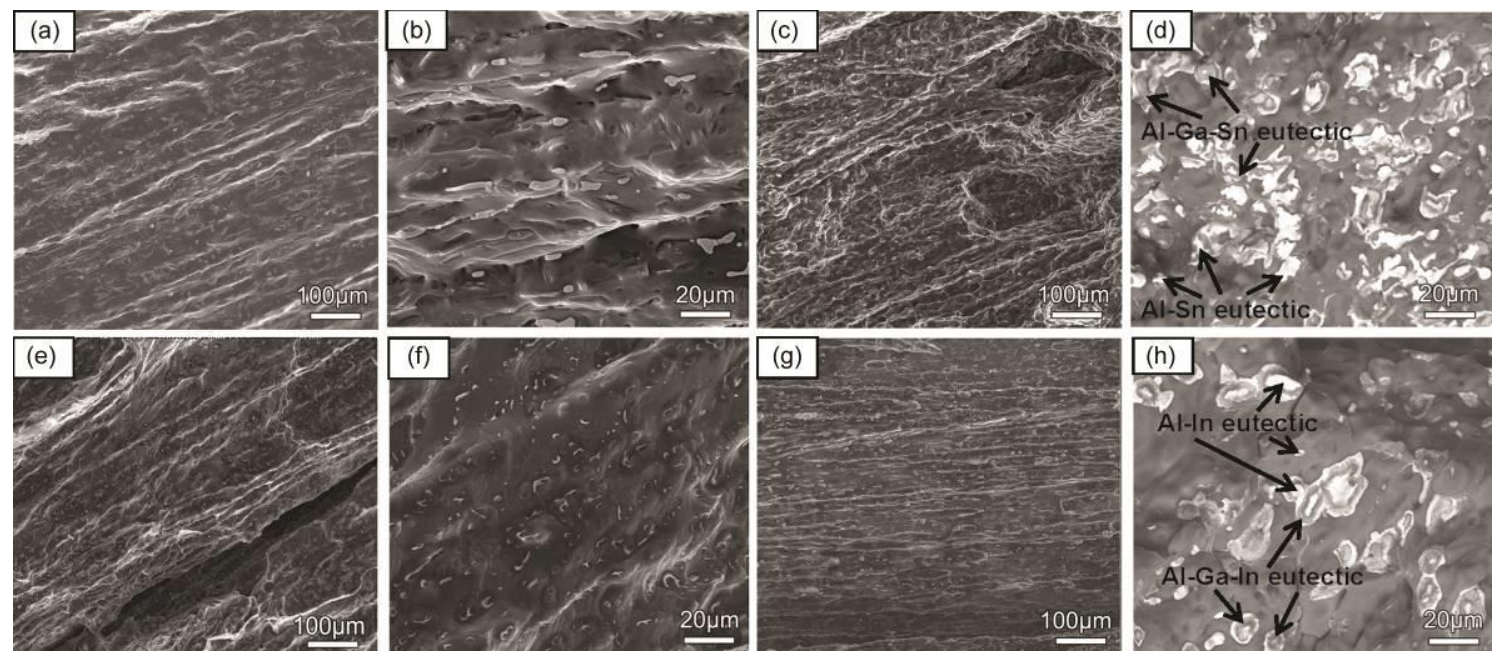

Fig. 2

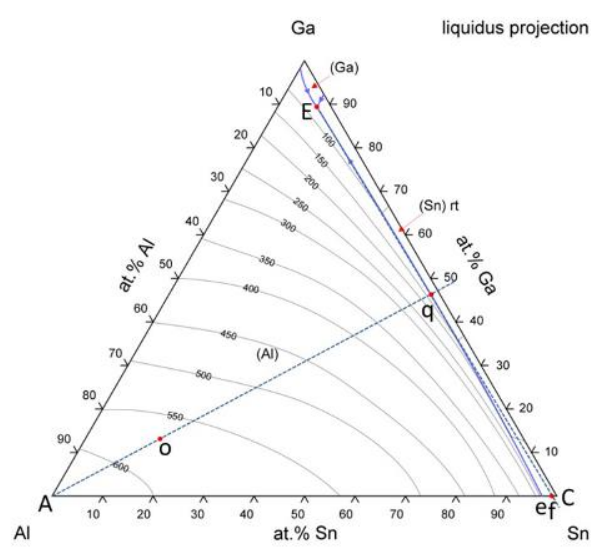

Fig. 3 

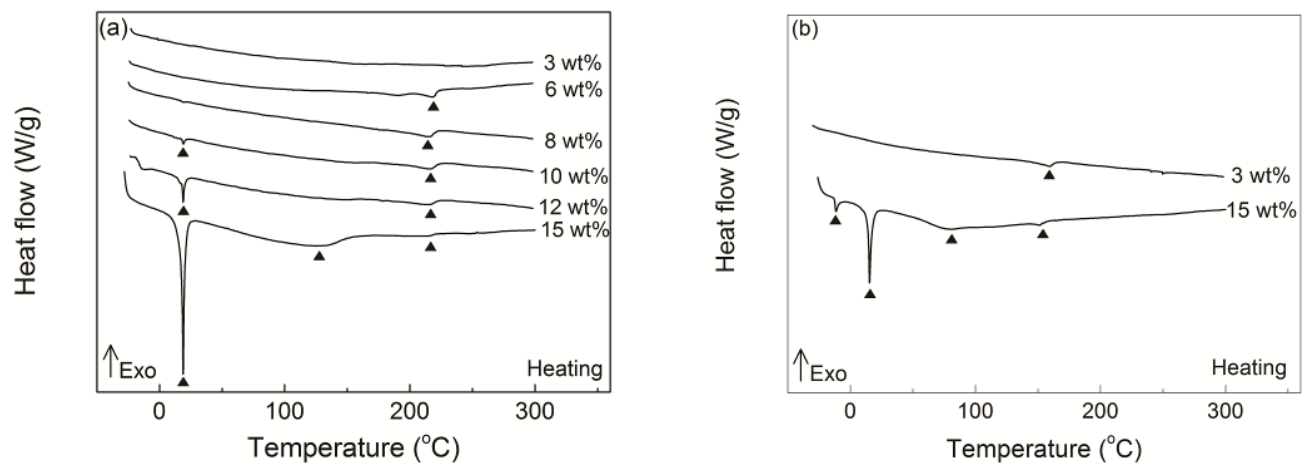

Fig. 4
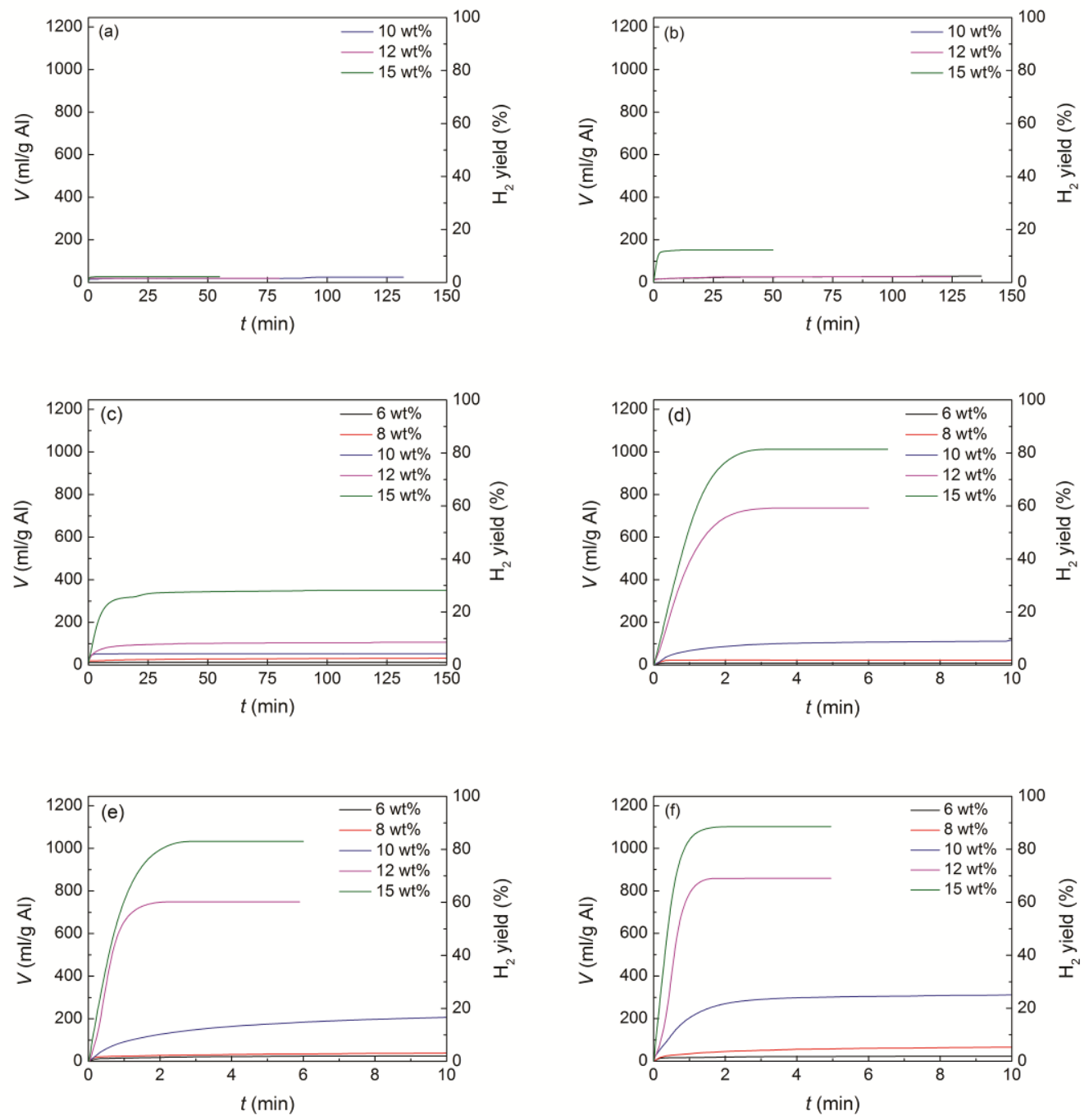

Fig. 5 


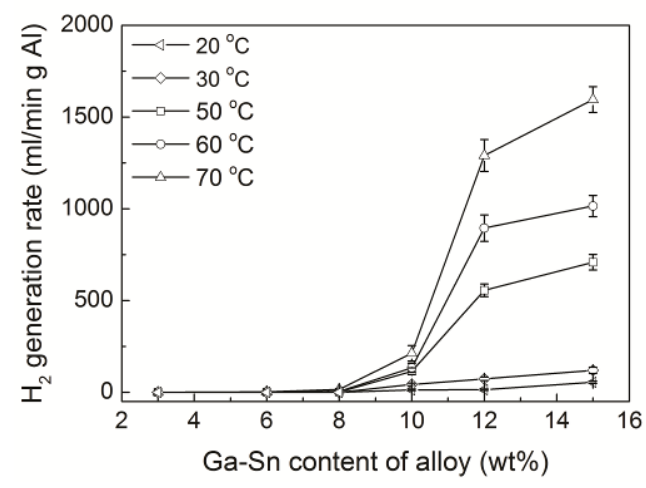

Fig. 6
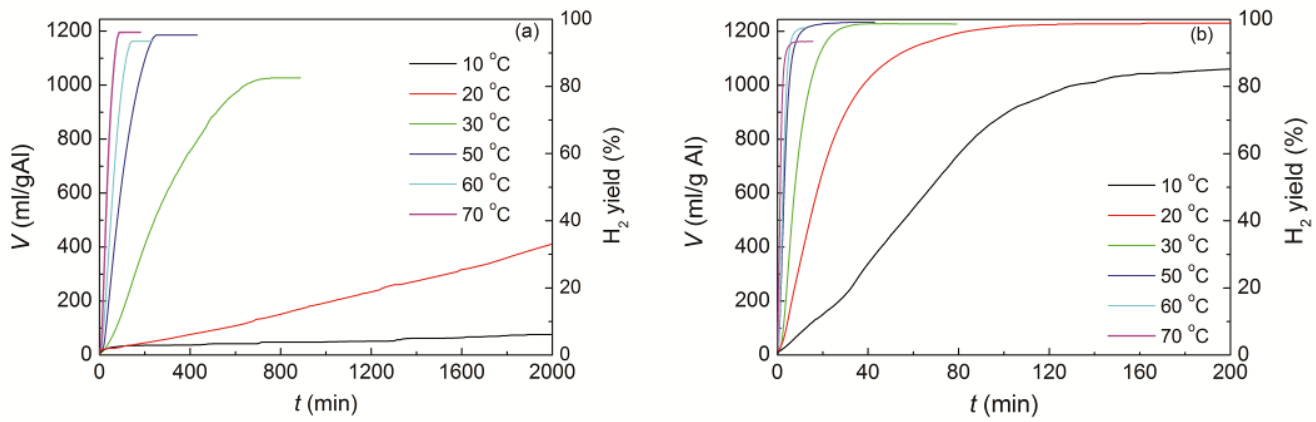

Fig. 7

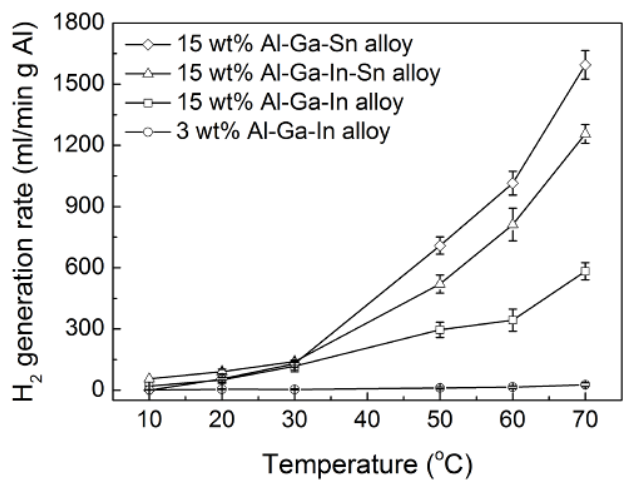

Fig. 8 